\title{
Exploring the dynamics of neighborhood ethnic segregation with agent-based modelling: an empirical application to Bradford, UK
}

\author{
Carolina V. Zuccotti ${ }^{1}$, Jan Lorenz ${ }^{2}$, Rocco Paolillo ${ }^{3}$, Alejandra Rodríguez Sánchez ${ }^{4}$ and \\ Selamawit Serka ${ }^{5}$
}

\begin{abstract}
How individuals' residential moves in space translate into overall segregation patterns, remains a key challenge in neighborhood ethnic segregation research. In this paper, we use agent-based modeling to explore this concern, focusing on the interactive role of ethnic and socio-economic homophily preferences and housing constraints as determinants of residential choice. Specifically, we extend the classic Schelling model to a random utility discrete choice approach to simulate the relocation decisions of people (micro level) and how they translate into spatial segregation outcomes (macro level). We model different weights for preferences of ethnic and socioeconomic similarity in neighborhood composition over random relocations, in addition to socioeconomic housing constraints. We formalize how different combinations of these variables could replicate empirically observed ethnic segregation scenarios in Bradford, a substantially segregated local authority in the UK. We initialize our model with geo-referenced data from the 2011 Census and use various measures of segregation to describe our results. As in the original Schelling model, we find that even mild ethnic preferences alone would lead to unrealistic ethnic oversegregation in Bradford. However, we demonstrate that such process can be altered in favor of less ethnic segregation when agents' preferences for socioeconomic similarity are slightly stronger than their preferences for ethnic similarity. We discuss the theoretical and policy contributions of our findings.
\end{abstract}

Keywords: neighborhood ethnic segregation, ethnic homophily, socioeconomic homophily, housing constraints, Bradford, Schelling, GIS

\section{Introduction}

What role do individuals' residential behaviors play in neighborhood ethnic segregation? This question has been at the core of migration and urban studies research. Yet, the current answer to it is partial. Segregation research-especially the one present in the UK-has been dominated by studies on segregation levels (e.g. Catney 2018, Simpson 2007, Harris 2017), neighborhood effects (e.g. Clark and Drinkwater 2002, Zuccotti and Platt 2017) and residential dynamics and neighborhood attainment (e.g. Coulter and Clark 2018, Zuccotti 2019). However, the link between micro-behaviors and emergent macro-phenomena have played a minor role in segregation research. In other words, there is limited understanding of how individuals' moves in space, mediated by

\footnotetext{
${ }^{1}$ Universidad Carlos III de Madrid (corresponding author: carolinaviviana.zuccotti@uc3m.es).

2 Jacobs University.

${ }^{3}$ Universität Bremen.

${ }^{4}$ Humboldt Universität zu Berlin.

${ }^{5}$ Hawassa University.
} 
their residential preferences and constraints (i.e. micro-behaviors), translate into the overall emergent segregation patterns that we observe (i.e. macro phenomena). Inspired by the field of analytical sociology - whose main aim is to understand what complex and intricated set of social processes and their interactions lead to emergent macro phenomena (Hedström and Bearman 2009, Manzo 2014) — our paper addresses this research gap through the case study of Bradford, UK. Specifically, we investigate what role individuals' residential moves, mediated by their ethnic and socioeconomic homophylic preferences and by socioeconomic housing constraints, play in the creation of Bradford's ethnic spatial structure. Both homophilic preferences and housing constraints are known to be key determinants of individuals' residential moves (Charles 2003, Krysan and Crowder 2017), and are therefore the focus of the present study. ${ }^{6}$

To achieve our goal, we use agent-based modeling (ABM). More specifically, we build on one of the earliest and most popular agent-based models: the Schelling $(1969,1971)$ model of segregation. The central intuition of ABM is that social order is build up from the unscripted actions of individual agents who constitute the social system and act in relation to others (Hedström and Bearman 2009: pp. 19). In ABM, agents are (or can be) heterogeneous, autonomous, physically conditioned by space, socially embedded in a network, and guided by realistic rules of behavior and decision processes. In contrast to other methods, $A B M$ allows one to define a rich and realistic set of micro specifications and deduce its high-level consequences (León-Medina 2017: pp. 160). The Schelling model applies this idea to the study of spatial segregation. The model allows simulating characteristics and preferences of individuals (agents) and to formalize the emergence of spatial segregation as an aggregated emergent phenomenon of their interaction (Huang et al. 2014, Macy and Willer 2002, Clark and Fossett 2008). In its original version (Schelling 1971, 1969), the most important preference is the fraction of members of the own (ethnic) group that an individual would want in the neighborhood (represented by the agent's threshold). People would stay in a neighborhood if the fraction of in-group members does not fall below their threshold, and relocate elsewhere otherwise. The Schelling model demonstrates that even mild individuals' preferences (i.e. low thresholds) for co-ethnics can cause high levels or even full ethnic segregation through the cascade effects originating from individuals' relocation decisions (further details on this mechanism in the Online Annex). ${ }^{7}$ A main lesson from this model is, therefore, that highly segregated societies do not necessarily stem from high levels of ethnic prejudice.

The Schelling model has been used mostly as a theoretical framework or for understanding spatial dynamics in a more conceptual way. New computational developments (see Drouhot et al. under review), and in particular the possibility to combine ABM interfaces (such as NetLogo) with empirical geo-referenced data (through GIS add-ins and shapefiles), allows implementing the Schelling model to the analysis of existing segregation dynamics, with real world data. We follow this approach in the present study, by combining the Schelling model with geo-referenced Census data (2011) on Bradford. More specifically, we extend the original version of the Schelling model of segregation to include both ethnic and socioeconomic preferences, as well as socioeconomic housing constraints, in modelling individual behavior (see also Aldén, Hammarstedt, and Neuman 2015, Bruch 2014, Fossett 2006). The availability of empirical Census data on both ethnic and socioeconomic compositions of neighborhoods allows us to do so. We implement a discrete choice version of the model (see also Bruch 2014): agents select whether to leave the current neighborhood and which neighborhood to move to using a utility function including the desired threshold for ethnic and socioeconomic similarity and weights for each dimension. The weights

\footnotetext{
${ }^{6}$ We are aware that there are other factors affecting residential moves and/or spatial segregation patterns overall, such as housing discrimination (Roscigno, Karafin, and Tester 2009), fertility, migration (Finney and Simpson 2009) and family relations (Peach 2005). We do not include these in our analysis to keep it more focused, and because of the limits of the analytical environment.

${ }^{7}$ As pointed out by Hegselmann (2017), the model likely goes back to Sakoda's work.
} 
quantify how important each dimension is for individuals. Housing constraints are further incorporated to regulate where agents can move to, based on their socioeconomic characteristics.

Bradford, a half-million populated Local Authority (LA) in the north of England, is an interesting case study to explore these dynamics. First, Bradford has a relatively high share of non-white ethnic minorities, around one quarter of its population, and is also one of England's LAs with the highest neighborhood ethnic segregation (Catney 2018, Zuccotti 2021, Lan, Kandt, and Longley 2020). Second, Bradford is one of the most deprived LAs in England: ${ }^{8}$ once an attractive location for migrants and their families in the postwar era, it later became an area of industrial decay, with increasing unemployment and poverty. Third, and most importantly, Bradford has been the target of effervescent debates about neighborhood ethic segregation, following the 2001 riots. These riots emerged as a consequence of the strong spatial association between ethnic concentration and neighborhood deprivation, housing discrimination, and increasing antagonism between ethnic minorities and White British individuals. Back then, in a series of reports, the government emphasized the fractured condition of communities, with the result that Asians and White British individuals were leading 'parallel lives' and self-segregating (Rattansi 2011). While these affirmations have been challenged (Phillips 2006), it remains an issue of debate what mechanisms are associated with the emergence and persistence of ethnic segregation in Bradford. Our study sheds new light on this.

Our analysis shows how the interplay of different micro-behaviors (motivated by homophilic preferences and housing constraints) can lead to varied emergent segregation patterns. We first show that an unrealistic scenario of ethnic over-segregation quickly emerges when agents' residential moves are based solely on their (mild) ethnic preferences, in line with the original Schelling model. However, when socioeconomic conditionings are considered, too, a more realistic segregation scenario emerges. Specifically, a main finding of our study is that when agents' preferences for socioeconomic similarity are slightly stronger than their preferences for ethnic similarity (i.e., when socioeconomic preferences weight more), ethnic over-segregation decreases and a segregation scenario closer to the empirical one observed in 2011 emerges. Our work shows that both ethnically and socioeconomically motivated residential choices are fundamental for understanding Bradford's overall ethnic segregation patterns. The implications of this outcome and possible mechanisms behind it are discussed in the next pages.

\section{Theory and background}

\subsection{Individuals' preferences and housing constraints in neighborhood segregation}

Different factors explain the spatial allocation of groups and its changes over time (Krysan and Crowder 2017). For the purposes of this paper, we focus on three of them: ethnic preferences, socioeconomic preferences and socioeconomic housing constraints.

Homophily - the tendency and preference of individuals to interact and share spaces with other that are similar-is known to apply to many categories, including ethnicity and socioeconomic background (McPherson, Smith-Lovin, and Cook 2001, Lazarsfeld and Merton 1954). Homophylic preferences are often developed over the life course, and they are strongly related to lived experiences and social relations built over time (Krysan and Crowder 2017). Homophilic preferences can be key drivers of neighborhood segregation: to the extent that individuals are raised in areas with certain ethnic or socioeconomic characteristics and interact with similar others (Belot and Ermisch 2009), this will also affect their residential choices and, in consequence, the overall spatial allocation of groups. Ethnic preferences, in particular, can also be associated with wanting to develop social networks and friendships with co-ethnics (Heath and Demireva 2013), reaffirming the own ethnic/religious identity, or increasing the subjective wellbeing (Knies, Nandi,

\footnotetext{
${ }^{8}$ https://ubd.bradford.gov.uk/about-us/poverty-in-bradford-district/ (last access December 9th 2021).
} 
and Platt 2016). At the same time, fear of discrimination or avoiding situations of harassment (Phillips 2006, Carling 2008), can also lead one to prefer a co-ethnic as a neighbor. Similarly, cultural and identitarian factors (Stephens, Markus, and Phillips 2014), as well as factors associated with ease of communication and social exchanges (McPherson, Smith-Lovin, and Cook 2001), can also explain why individuals might prefer neighborhoods that reflect their own socioeconomic status. These arguments also emerge in the social reproduction literature, where it is argued that people's priority is to maintain their own social class (Stephens, Markus, and Phillips 2014, Goldthorpe 2000). Residing next to individuals with similar socioeconomic characteristics - with whom they can share spaces like schools, social clubs and job centers, and create social ties (Lin 2001) — can be a means towards this aim. ${ }^{?}$

As for the housing constraints considered in this study, they express the socioeconomic structural component of segregation. Having more socioeconomic resources means that individuals can afford wealthier neighborhoods (which are often whiter too), or that they can more freely choose where to go (Crowder, South, and Chavez 2006). Socioeconomic housing constraints are therefore a main factor that explains why individuals with different socioeconomic resources live in different locations.

All in all, the existence of ethnic and socioeconomic preferences on the one hand and housing constraints on the other-which we consider separately in our modeling-, imply that neighborhood ethnic segregation might depend on how socioeconomic resources distribute across groups (Krysan and Crowder 2017). More generally, one could hypothesize that if in a certain city all ethnic minorities are poor and all majoritarian white are rich, this might more easily lead to full ethnic segregation; however, if groups are mixed in socioeconomic terms, this may help decrease ethnic segregation, since ethnic preferences will interact with socioeconomic preferences and with housing constraints (Malmberg and Clark 2020). In the UK, ethnic minorities are more often found in neighborhoods with higher deprivation (Manley 2021, Jivraj and Khan 2013), a fact partly explained by their often-lower socioeconomic resources. However, high-status ethnic minorities also use their resources to improve their neighborhood (i.e. move to less deprived/whiter areas), in line with spatial assimilation-even though their probabilities of improvement remain lower compared to those observed for white Britons (Zuccotti 2019, Coulter and Clark 2018). These findings point to combined explanations for neighborhood ethnic segregation in the UK, associated with both ethnic and socioeconomic homophilic preferences and with housing constraints.

\subsection{Previous studies building on the Schelling model}

The role of socioeconomic resources has been explored by different studies dealing with the Schelling model of segregation. In their study of Swedish cities, for example, Malmberg and Clark (2020) show why income-based sorting can be a factor that counteracts the chance of full segregation as predicted by the Schelling model. They demonstrate that ethnic concentration decreases the housing price of neighborhoods, and this attracts low-income individuals both with and without an ethnic minority background. Conversely, white neighborhoods become unaffordable for low-income groups, but attractive for individuals who have the means to access them, be these ethnic minorities or not.

The socioeconomic dimension has also been included in several extensions to Schelling's model to reflect more realistic scenarios of segregation. These models include housing costs as an empirical constraint to the relocation moves of people (Bruch and Mare 2009b), as well as additional preferences - next to the ethnic ones_-associated with neighborhoods' quality and amenities, or socioeconomic and status composition, among others (Chen et al. 2005, Benard and Willer 2007). In particular, this stream of literature is interested in formalizing how the interaction between

\footnotetext{
${ }^{9}$ There are alternative factors that may neighborhood choice, such as low-status aversion or high-status attraction (for details see Galster and Turner 2019). They may be the object of future study.
} 
unequal income distribution, different preferences and population structure can contribute to spatial sorting between majority and minorities or differences within ethnic groups. Bruch (2014), for example, builds a Schelling-type model where black and white people select neighborhoods based on both racial preferences and neighborhood wealth. Results show that with sufficiently high within-race income inequality, an increase in between-race income inequality is associated with higher probability for lower income black to relocate in an ethnically homogeneous neighborhood, while the probability decreases for higher status black. Outcomes vary depending on the size of minority.

Fossett $(2011,2006)$ builds a model with three ethnic groups, where ethnic preferences, preference for neighborhood socioeconomic status and housing quality interact. He addresses the consequences of such preferences with different purchasing power associated with the socioeconomic status of agents, with minorities given less resources, and all agents aiming at high quality neighborhoods. He shows that native high-status agents can more easily afford high quality neighborhoods, which hence become also ethnically homogeneous. On the contrary, low income minorities end up in more affordable neighborhoods that become more ethnically diverse but economically poor (Fossett 2006). Another study with the same model manipulates different scenarios of income inequality between groups, showing patterns of hyper-segregation, i.e. agents with lower income end up in both predominantly ethnic and deprived neighborhoods (Fossett 2011).

\section{Key aspects of our agent-based model}

In our agent-based model we follow this stream of literature linking ethnic and socioeconomic characteristics. The aim is to understand whether and how ethnically and socioeconomically motivated residential behaviors-potentially conditioned by housing constraints-playout in the emergence of ethnic segregation in Bradford. Our model has the following key aspects. First, we identify socioeconomic status (SES) as one dimension of homophily preference, next to the ethnic dimension. This means that agents in our model consider both ethnic and socioeconomic preferences when evaluating their own residential location and a potential move. Second, we consider a random component that represents other unknown factors that might influence individuals when deciding whether to relocate, and we model the weight of either ethnic or socioeconomic preferences over this random component. Third, we consider housing constraints, that is, the affordability and status suitability of relocation moves associated with SES. Finally, we initialize our model with the distribution of the population between ethnic groups, and the distribution of socioeconomic status between different ethnic groups, which is possible thanks to the incorporation of Census geo-referenced data into the ABM.

As regards ethnic and SES preferences, we consider two aspects: agents' preference thresholds and the weights attributed to SES and ethnic preferences. Agents' thresholds refer to the minimal fraction of members of the same group that an individual wants in order to stay in the neighborhood. The threshold $(\theta)$ in our model divides between negative utility (fraction of similar ones below threshold) and positive utility (fraction of similar ones equal or above threshold). Agents search for a new location when they perceive negative utility. Then they compare their location with an alternative and choose the one with higher utility. Our model also provides a weight to the role of preferences-be these ethnic or socioeconomic (Bruch and Mare 2009a, Van de Rijt, Siegel, and Macy 2009, Bruch and Mare 2006). Even with the same threshold for ethnic and socioeconomic similarity in the neighborhood, agents in our model can give a different importance to ethnicity and socioeconomic characteristics when choosing for a new residence or evaluating their own. In the utility function that we use, weights are expressed in the values of parameters Betas $\left(\beta_{\mathrm{Eth}}, \beta_{\mathrm{SES}}\right)$.

Our utility function also considers a random component $(\varepsilon)$ to the utility of agents to a particular location, which models any other factor that could influence the utility of a neighborhood. This 
includes, for example, any additional neighborhood amenities (i.e. schools, churches, green areas) that match different household compositions or lifestyles, but also preference towards neighborhoods' openness to diverse ethnic groups (associated with different levels of discrimination in the housing market). The lower the Betas, the higher the weight of the random component will be in the agent's decision, so that the decision either to remain or select another neighborhood will be taken randomly.

As regards housing constraints, in our model this is referred to as "tie-houses-to-SES". With this specification - that we use in our simulations-we acknowledge that individuals are often spatially constrained in terms of the types of locations and houses they can move to, given their socioeconomic resources. In other words, when housing constraints are switched on in our model, individuals are constrained to move to free spots that correspond to their own socioeconomic status. This is what would normally happen in real life. Note that, although in reality housing constraints and socioeconomic preferences are related, they are considered separately in our model (see also Benard and Willer 2007). It might then happen that a high SES agent finds a high SES house, but that the neighborhood overall is predominantly low SES (hence not satisfying the agent's SES preferences).

Finally, ethnic and socioeconomic compositions obtained through empirical data are a key aspect in our model. Specifically, we inform our model with empirical neighborhood data on ethnicity and socioeconomic resources of individuals, hence narrowing down the possible scenarios that we can formalize to the Bradford case.

\section{Bradford: data and key measures}

Our analysis uses aggregated Census data (2011) obtained for Bradford at small geographical levels, the Lower Layer Super Output Areas (LSOAs). For each LSOA we collected information on SES by ethnic group. We identified four ethnic groups - White British, Asian, Black, and Other ethnic groups (includes other White and mixed groups) — and three SES groups - High, Mid and Low. Our analysis is therefore based on Census information making up $\mathbf{1 2}$ categories for each $\boldsymbol{L S O A}$. Ethnicity is measured with a question on ethnic self-identification; SES is based on the National Statistics Socio-Economic Classification (Erikson and Goldthorpe 1992), and applies to individuals aged 16+ (except for those who never worked, the long-term unemployed and full-time students). Figure 1 shows the distribution of SES categories by ethnic group in Bradford. The SES distribution is quite similar across groups, even though the proportion of individuals without a valid SES is higher among ethnic minorities. Further details about the data, variables, and their limitations, are discussed in the Online Annex. 


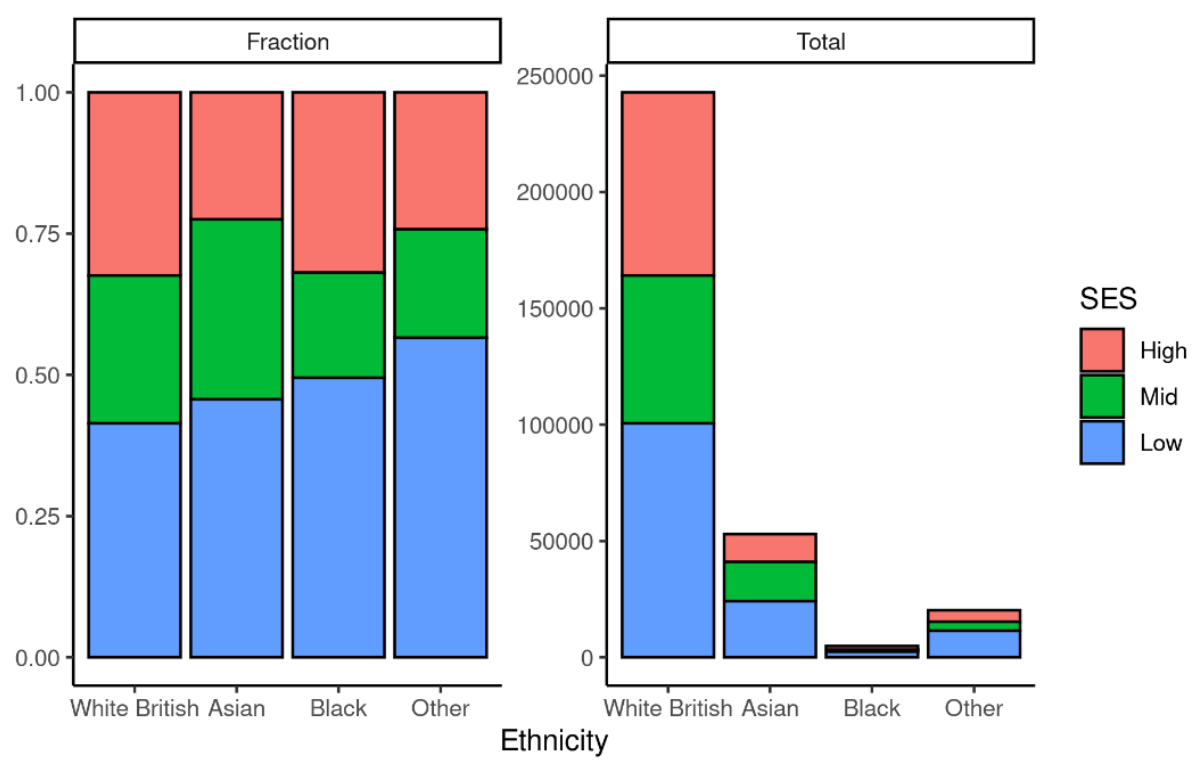

Figure 1: Distribution of SES categories by ethnic group Bradford, 2011 $N=242835$ (White British), 52954 (Asian), 4880 (Black), 20252 (Other)

The key outcome variable of our ABM is the distribution of ethnic minorities in LSOAs, which we measure with the fractions of ethnic groups in LSOAs (see Figure 2). Further on, we focus on three indices: Dissimilarity Index, Average Local Simpson Index and Moran Index of spatial autocorrelation.

The Dissimilarity Index is a measure of the evenness with which an ethnic group is distributed across geographic areas (LSOAs) that make up a larger area (Bradford LA). The index indicates the percentage of members of that group that should relocate to let the distributions at the LSOA levels match the distribution at the town level. The Dissimilarity Index is highest for Asians (0.66, see Figure 2).

The Simpson Index, which can be calculated for each LSOA (local) and for the whole town, is a measure of ethnic concentration. It expresses the probability that two randomly selected individuals from the LSOA/town have the same ethnicity. To calculate this index we only consider White British, Asians, and Blacks, leaving outside "other ethnic groups". We do so upon the consideration that individuals from this group are less likely to recognize each other as similar in terms of ethnic preferences. The town-wide Simpson Index is $S_{\text {Town }}=0.6 .{ }^{10}$ This number serves as a reference to compare with the Average Local Simpson Index that we use in our study, which is the population weighted average of the Local Simpson Index values in all LSOAs. When it is much larger than the town-wide Simpson Index, this indicates strong local concentration (see also red areas in Figure 2). In Bradford, the Average Local Simpson Index it is $S=0.726$. This means that the probability that a randomly selected pair of individuals from the same LSOA is from one ethnic group is $72.6 \%$, while this would only be $60 \%$ when the pair is sampled randomly from the whole town.

The Moran Index (Moran-I), finally, computes the spatial autocorrelation, i.e. the tendency for neighboring areas to report similar values for a certain characteristic such as ethnic concentration, across LSOAs. It ranges from -1 to 1 . The value of 0.78 for the Local Simpson Index in Bradford denotes high spatial autocorrelation based on ethnicity. All indices' formulas are in the Online Annex. The numbers in Figure 2 build the basis for our data-driven model building and calibration.

10 The focus on the population with a valid SES has notable consequences for the Bradford's town-wide Simpson Index which would be only $S=0.48$ otherwise, mainly because of the higher share of Asians in the total population. 


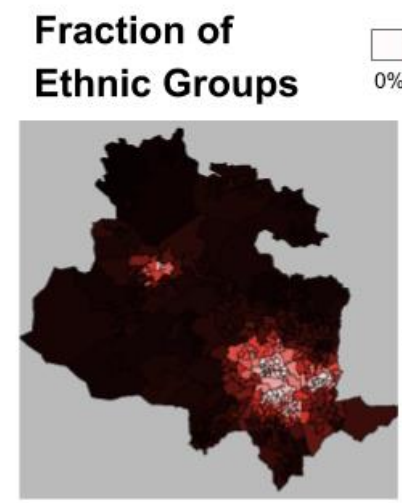

\section{White British}

Fraction 0.757 Moran-1 0.84

Dissimilarity 0.589

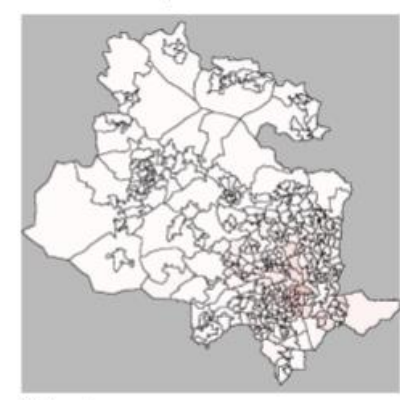

\section{Black}

Fraction 0.015 Moran-I 0.732

Dissimilarity 0.417

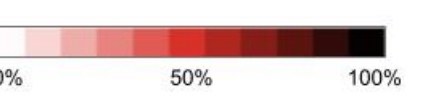

Simpson Index

\section{Ethnic concentration}

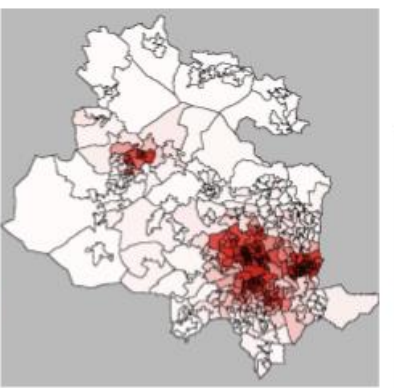

Asian

Fraction 0.165 Moran-I 0.795

Dissimilarity 0.658

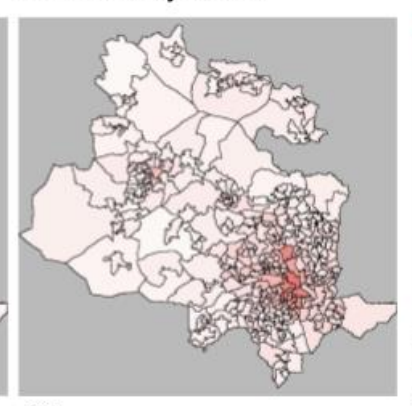

Other

Fraction 0.063 Moran-1 0.743

Dissimilarity 0.276
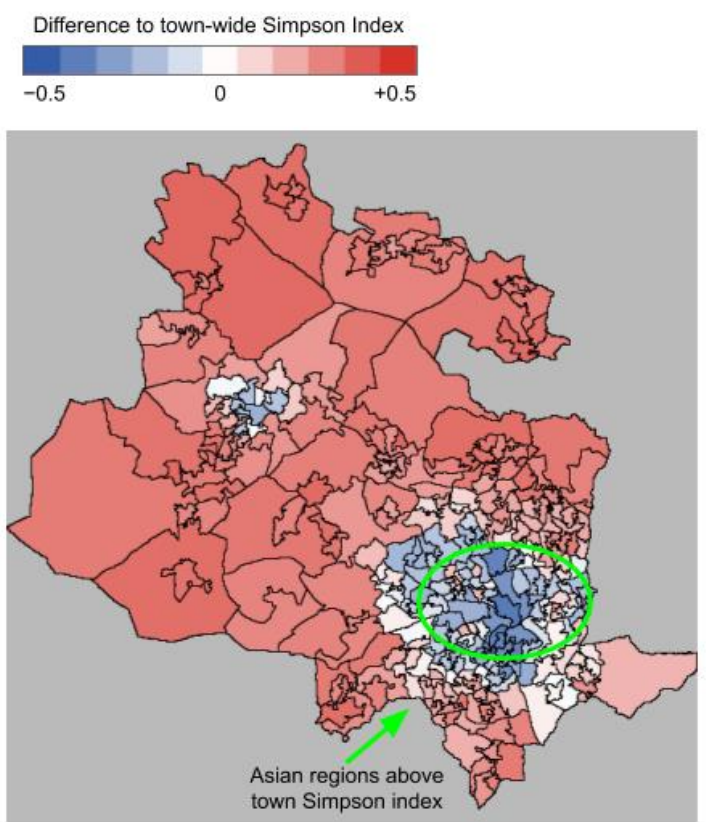

Moran-Index of Local Simpson Index 0.786

Average Local Simpson Index 0.726

Town-wide Simpson Index 0.6

Note: All Simpson Index computation exclude "Other"

Figure 2: Distribution of ethnic groups and segregation indices. Bradford, 2011

\section{Agent-based model}

\subsection{Model setup}

Our ABM is built in NetLogo 6.1.1 (Wilensky 1999), which is a modeling environment made for agent-based modeling and simulation. In the model, each agent represents an individual specified by ethnicity ("WHITEB", "ASIAN", "BLACK", or "OTHER"), socioeconomic status ("LOW", "MID", or "HIGH"), and an individual threshold value that quantifies the minimal fraction of similar neighbors (in term of ethnic or socioeconomic status) the agent needs to be satisfied with their current location. ${ }^{11}$ Each agent is located in one of the 306 LSOAs in Bradford, which are loaded into the model upon initialization using NetLogo's GIS extension. The neighborbood of an agent is constituted by all other agents in the same LSOA and, with a lower weight those agents in geographically neighboring LSOAs.

At each unit time step, agents make relocation choices. We model a unit time step such that, on average, every agent makes one relocation choice per time step. An agent's decision to relocate is modeled as a two-step process: the decisions to search and the decision to move. First, the agent assesses the utility of their current residence. When utility is positive, the agent stays, and the second step is skipped. When utility is negative, the agent compares their current residence to a random alternative and chooses the one with larger utility. With the two-step process, we unite two traditions of relocation models. In the first tradition (Schelling's original model), agents only decide to leave to a new place once their neighborhood doesn't satisfy their utility (step one), without

\footnotetext{
11 The threshold is an individual static variable of each agent. We assume that thresholds are heterogeneous among agents. As thresholds should be between 0 and 1, a natural assumption is, that they come from a Beta distribution. The agents' thresholds are randomly drawn upon initialization.
} 
checking if utility would improve. In the second tradition, subscribing to discrete choice models (Xie and Zhou 2012, Bruch and Mare 2009a), agents always compare their current residence with other options (step two), selecting the one with the highest utility. In our model, they only do this if they already have negative utility at their current location. ${ }^{12}$

Formally, an agent with ethnicity $X$, socioeconomic status $Y$, and threshold $\theta$ computes utility for a residence in LSOA $i$ as

$$
U_{X, Y, \theta}(i)=\beta_{\mathrm{Eth}}\left(P_{i}^{X}-\theta\right)+\beta_{\mathrm{SES}}\left(P_{i}^{Y}-\theta\right)+\varepsilon,
$$

where $P_{i}^{X}$ is the fraction of the population with the same ethnicity, $P_{i}^{Y}$ the fraction of the population with the same socioeconomic status and $\varepsilon$ is the unobservable utility of the agent. The first two terms on the right-hand side are the observable utility. The parameters $\beta_{\text {Eth }}$ and $\beta_{\text {SES }}$ represent the weights for similarity in ethnicity and similarity in socioeconomic status in the relocation choice in comparison to the random component $\varepsilon$ (Manski 1977).

In step one of the relocation decision, the agent decides to search when $U_{X, Y, \theta}(i)<0$. In step two, the agent selects an LSOA $j$ to potentially move to, based on a random probability proportional to the number of free residences over all districts. ${ }^{13}$ With the option tie-houses-to-SES switched on, the model keeps track of three different types of houses, one for each SES. That means, e.g., an agent of SES HIGH will only search for free houses for individuals of SES HIGH. The agent relocates to district $j$ when $U_{X, Y, \theta}(j)>U_{X, Y, \theta}(i)$, leaving a spot then available in district $i$. Utility increases linearly with $P_{i}^{X}$ as well as with $P_{i}^{Y}$. Thus, low similarity in ethnicity can be compensated by high socioeconomic similarity and vice versa. Unobservable utility $\varepsilon$ represents all unknown factors influencing the agent. Whenever utility is assessed, a random number for $\varepsilon$ is drawn from a standard Gumbel distribution. ${ }^{14}$ The lower $\beta_{\mathrm{Eth}}$ and $\beta_{\mathrm{SES}}$ are, the stronger is the impact of the random term. With $\beta_{\text {Eth }}=0$, ethnic similarity doesn't influence the relocation decision, for $\beta_{\mathrm{SES}}=0$, socioeconomic composition doesn't matter. A random term in the utility function is a standard assumption in discrete choice models to represent how people, though maximizing utility, might not always select the best option based on observable utility (Hess, Daly, and Batley 2018, Train 2009); it is also well-established in empirical studies of residential mobility (Frankhauser and Ansel 2016, Boschman and Van Ham 2015). In our case, it is reasonable to treat the ethnicity OTHER as done for the Simpson index: assuming they will perceive themselves as much less similar. Therefore, we set $\beta_{\text {Eth }}=0$ when $X=$ OTHER. ${ }^{15}$

The random term of unobservable utility and the random selection of alternatives make ours a stochastic model. Nevertheless, our model reaches segregation patterns looking like stochastic equilibria. That means, fractions of ethnicities stay constant, although every time step agents are still moving. A deeper mathematical analysis of equilibria and their stability is outside the scope of this paper. Note also that we do not model changes in the SES of individuals nor changes in the SES of houses. Such processes are of course relevant in the real world related to rising unemployment, upward mobility, and degradation or gentrification of neighborhoods. Given the already complex nature of our model, we leave these additional factors for future research. We provide additional technical descriptions of the model's implementation in the online Annex.

\footnotetext{
12 In the model, we provide a switch to make agents always move and a switch to make them always search.

13 The probability is additionally weighted by the fractions of those with the same ethnicity and those with the same socioeconomic status analog to the computation of utility. This models that an agent might receive recommendations which come from ethnic of socioeconomic peers. The feature can be switched off with the parameter ethn-sesrecommendations.

${ }^{14}$ The Gumbel distribution is also known as generalized extreme value distribution type-I. It has a mean of 0.577 and a standard deviation of 1.283. In decision step 2, two random numbers are compared, one for each alternative. The difference of two Gumbel random variables has a logistic distribution with mean zero and standard deviation 3.29.

15 The model includes a switch to treat OTHERS like a normal ethnic group.
} 


\subsection{Analysis}

We performed a parameter exploration to find a possible explanation of how ethnic residential segregation levels similar to those empirically observed in Bradford could emerge even from a counterfactual maximally non-segregated town, that is, from a situation in which each LSOA has the same ethnic composition (Edmonds et al. 2019, Epstein 2006). We searched for a combination of the parameters $\mu_{\theta}$ (average threshold), $\sigma_{\theta}$ (heterogeneity of thresholds), $\beta_{\text {Eth }}$ (weight for ethnic similarity), $\beta_{\mathrm{SES}}$ (weight for socioeconomic similarity), and tie-houses-to-SES. To that end, we scaled down Bradford's population by 10 to speed up computations. So, every simulation ran with about 32,180 agents, on average 105 per LSOA. ${ }^{16}$ The exploration started with reasonable parameters settings, based on educated guesses or plausible arguments. The resulting outcome was assessed qualitatively looking at the spatial patterns and some macroscopic segregation indicators. Next, configurations were chosen narrowing to a systematic scanning in a limited parameter range. ${ }^{17}$ Our exploration ended with the specification of a main parameter constellation that best approximates to Bradford's spatial patterns in 2011. In the following, we first present this constellation and show how it matches the empirical segregation pattern in Bradford. Afterwards, we decompose this parameter constellation to explain the emergent mechanisms: First, we analyze ethnic preferences alone and threshold heterogeneity; next, their interplays with socioeconomic preferences and socioeconomic housing constraints. While all four ethnic groups are considered in the coming analyses, we focus our discussion on the largest group, the Asians.

\subsubsection{Main parameter constellation}

The following parameters reproduce several characteristics of Bradford's empirical situation of ethnic segregation in 2011: $\mu_{\theta}=0.3, \sigma_{\theta}=0.1, \beta_{\text {Eth }}=8, \beta_{\mathrm{SES}}=12$, tie-houses-to-SES switched on. ${ }^{18}$ The standard deviation of $\sigma_{\theta}=0.1$ implies that less than $2 \%$ of all agents are already satisfied with less than $10 \%$ similar, while also less than $2 \%$ would demand more than $50 \%$ similar to stop searching for other options. The outcome of the simulation after 2,540 timesteps is shown in Figure 3. Simulation outputs almost stabilized at this stage, so the model seems to be close to a stochastic equilibrium. A deeper theoretical analysis specifically about the equilibria of the model is beyond the scope of this study. A detailed description of Figure 3 and steps to reproduce the simulation are shown in the Online Annex. Furthermore, our NetLogo model is freely available along with supplemental material in: https://github.com/janlorenz/Schelling_on_GIS.

\footnotetext{
${ }^{16}$ We tested extensively that simulation runs are like simulations with the full population.

${ }_{17}$ We refrained from implementing an automatic optimization for this study for two reasons: First, computation time is long, and (as we see later) stabilization of parameters is difficult to assess automatically. Second, a general performance measures comparing data and simulation is difficult to define properly. That could be an option in future studies with a more mature understanding of model dynamics.

${ }^{18}$ We set free-space $=0.05$ and neighbor-weight $=0.17$ after some exploration. A further analysis of these parameters' impact is beyond the scope of this study.
} 

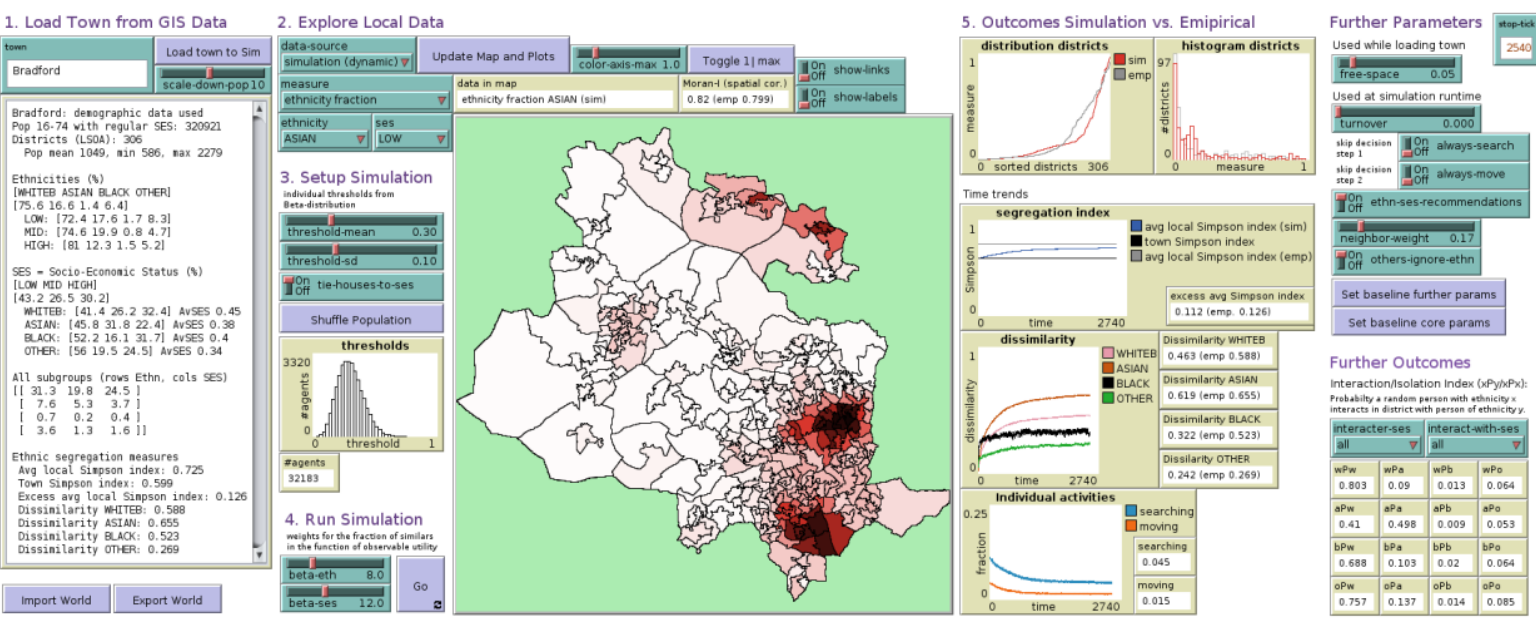

\section{Figure 3: NetLogo Interface, and simulation outcome at time step 2,540 with the main parameter constellation. The map shows the fraction of Asians.}

Figure 3 shows two smaller clusters of LSOAs in the north and two bigger clusters in the southeast are visible with more than 60\% Asians (central map), surrounded by LSOAs with around 30$50 \%$ of Asians. Some regions exist with $4-8 \%$ of Asians. Most of the other districts have close to zero Asians. This is similar to Bradford's empirical configuration in 2011 (see Figure 2). Figure A1 (in the Online Annex) shows the time evolution of the fraction of Asians in a sequence of maps to provide more detail on ethnic clustering. It also provides the outcomes of three other simulations run with the same parameters to demonstrate how they would not differ in terms of segregation levels, despite random fluctuations in the geographic configuration. The exact geographical configuration of ethnic clusters evolves to a large extent based on reinforcement of initial random fluctuations.

The outcomes of the simulation shown in Figure 3 show that levels of spatial segregation of Asians close to empirical data emerge from a spatially equalized population with intermediate preferences for ethnic similarity $\left(\beta_{\text {Eth }}=8\right)$ but even stronger preferences for similarity in socioeconomic status $\left(\beta_{\mathrm{SES}}=12\right)$. Segregation happens even though agents are on average already satisfied with a mild preference of $30 \%$ similar neighbors $\left(\mu_{\theta}=0.3\right)$, so that on average an agent would be fine with living in an LSOA as a minority concerning ethnicity and socioeconomic status-Asians and White British alike. The Moran Index of spatial autocorrelation for the fraction of Asians is 0.82 in the simulation, very similar to the empirical value of 0.799 (note that all measurements refer to a population with a valid SES). The Figure also shows that the simulated distribution of Asians is quite similar to the empirical distribution (see Section 5. Outcomes Simulation vs. Empirical), with the difference that the simulation shows slightly more districts with less than $10 \%$ Asians but slightly less with 10-60\% Asians. Looking at other measures, the average local Simpson Index starts with 0.599, and then it increases over time up to the level 0.711 close to empirical observations in Bradford in 2011. As in Bradford's empirical data, the dissimilarity of Asians grows highest, with White British second. The small fraction of Blacks has the third largest dissimilarity and other ethnic groups the lowest, which coincides with empirical observations. Interestingly, the dissimilarity of ethnic groups in the category "Other" also increases over time, although in our simulation these agents do not consider ethnic similarity in their decision to relocate, differently from the other three groups. The fraction of agents relocating declines over time because people tend to be satisfied. After the 2,540 time-steps still $4.5 \%$ of agents decide to search an alternative and $1.5 \%$ of the people move.

Why do these segregation patterns emerge out of equally distributed ethnic groups in LSOAs, that is, out of an initial ethnically non-segregated Bradford? A reinforcing mechanism is at play, following four basic steps: 
1) Random fluctuations happen through random draws of unobservable utility, which perturbs the perfect equality of LSOAs' demographic compositions.

2) An agent who searched for a new location is more likely to move to a LSOA with more agents of their kind (in ethnicity or socioeconomic status), even if they would remain unsatisfied afterwards. Agents who have positive observable utility tend to stay. Staying is very likely for White British individuals but unlikely for Asians (and Blacks) in the initial condition (due to White British individuals' higher numerosity). Thus, in the beginning, Asians will move more than White British individuals and more likely to districts with slightly more Asians. This mechanism can drive an increase in the fraction of Asians in LSOAs with few Asians.

3) Once the fraction of Asians in a district exceeds the average threshold of 0.3, Asians in that district are more likely to be satisfied and to not search anymore for alternatives. Such a district becomes persistently more attractive for other unsatisfied Asians, in addition to Asians there already satisfied. White British individuals also have positive utility there but, due to their higher numerosity, there are many more options equally satisfying for them than for Asians. This mechanism spurs the increase of the fraction of Asians in LSOAs with already a sizable fraction of Asians.

4) Finally, if the fraction of Asians approaches $70 \%$ (one minus the average threshold) most White British are likely to receive negative utility from the LSOA's ethnic composition so to start searching better alternatives. This drives the evolution towards an all-Asian district.

If these mechanisms would have continued to work alone, Bradford would have ended up with all Asians and White British concentrating in fully homogeneous districts (see more details in section 5.2.2). However, the mechanisms of socio-economic similarity and housing constraints have mitigated this reinforcement. Specifically, some weight on socio-economic preferences can mitigate the drive towards full ethnic segregation because individuals now also draw utility from living with neighbors of similar socioeconomic status, even when these have another ethnicity. The role of housing constraints (tie-houses-to-SES) has a smaller impact on ethnic segregation: the emerging patterns of ethnic segregation ultimately rely, thus, on preferences of agents rather than stemming from their affordances against housing constraints. However, without housing constraints we obtain a much higher socioeconomic segregation than observed in reality. Hence, while not affecting ethnic segregation so much, housing constraints do prevent this dynamic towards districts with unrealistically high fractions of low and high SES individuals. The inclusion of this factor provides, therefore, with a more realistic scenario of Bradford's ethnic and socioeconomic structure. We point this out more explicitly in the following.

\subsubsection{Other parameter constellations}

In the following, we show more simulation output starting with ethnic preferences alone and a homogeneous threshold. Then we introduce, step by step, heterogeneous thresholds, preferences for socioeconomic status, and tie-houses-to-SES, to arrive at the final parameter constellation presented above.

Figure 4 shows simulation output with different weights for ethnic preferences $\left(\beta_{\text {Eth }}=4,8,12\right.$ ) and no socioeconomic preferences $\left(\beta_{\mathrm{SES}}=0\right)$. Further on, simulations ran with a homogeneous threshold $\mu=0.3\left(\sigma_{\theta}=0\right)$ or heterogeneous thresholds $\left(\sigma_{\theta}=0.1\right)$ as in the final constellation. All simulations ran for 1,260 time-steps. Results show two qualitatively different outcomes. For high ethnic similarity weights, Asians gather and satisfice in several LSOAs with $20 \%$ to $30 \%$ Asians with no larger Asian fraction in other LSOAs. For low weights and thus more random fluctuations, almost all Asians finally end up in 100\% Asian districts. This result may appear counterintuitive because one might think that a higher weight for ethnic similarity would indeed trigger more ethnic segregation. The reason is that without random fluctuations, the mechanism (4) could not kick in and no LSOA would reach the threshold at which White British individuals massively leave. Random fluctuations can create a seed for all-Asian districts, making also neighboring districts attractive for Asians. The heterogeneity of thresholds seems to contribute to this, as visible in 
Figure 4. For the intermediate weight of $\beta_{\mathrm{Eth}}=8$, all-Asian districts only emerge under heterogeneous thresholds. The case with heterogeneous thresholds is also interesting as shown in the gray extra box in Figure 4: after 300 timesteps the situation looks as for homogeneous thresholds. Only after about 800 timesteps the dissimilarity index of Asians quickly increases and the whole town shifts to full segregation. Such sudden drastic changes are a common possibility in dynamic models. Also, the small Black population could form a cluster with one all-Black district in this simulation run.

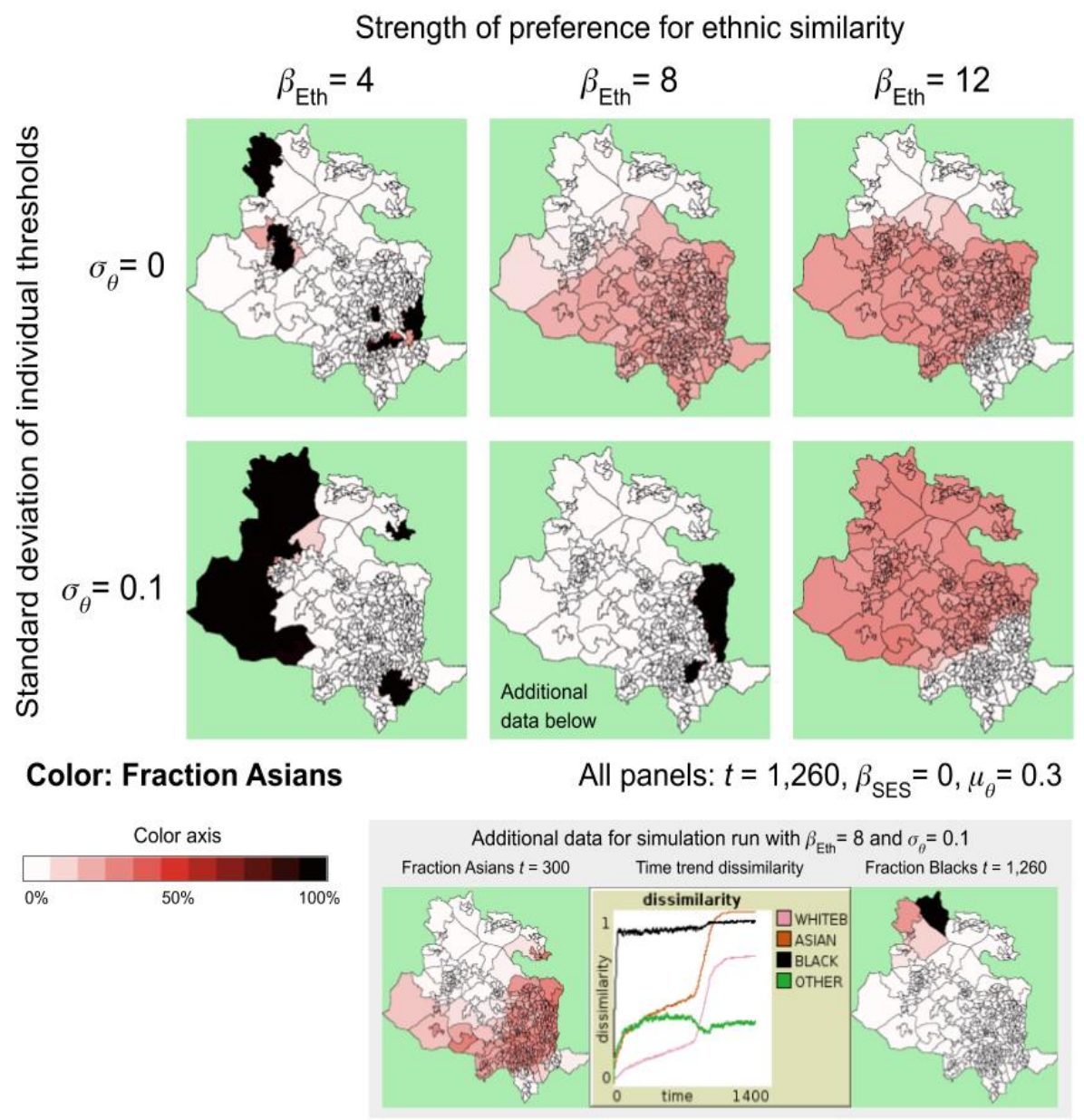

Figure 4: Exploration of the preferences for ethnic similarity and threshold heterogeneity focusing on the fraction of Asians including further details for one simulation at the bottom.

In Figure 5 we show the effect of preferences and housing restrictions concerning socioeconomic status. While Figure 4 showed that an intermediate level of $\beta_{\text {Eth }}=8$ together with threshold heterogeneity $\sigma_{\theta}=0.1$ enabled the emergence of all-Asian districts, this exaggerated the empirical situation of ethnic segregation in Bradford, as no ethnically diverse districts remained. Figure 5 shows the effects of increasing weight for socioeconomic similarity $\beta_{\mathrm{SES}}$. Further on, it introduces that houses are tied to the socioeconomic status of residents. Both the condition $\beta_{\mathrm{Eth}}=8, \beta_{\mathrm{SES}}=$ 12 with tie-houses-to-SES and the condition $\beta_{\mathrm{Eth}}=8, \beta_{\mathrm{SES}}=8$, without tying-houses-to-SES, deliver both results close to empirical observations. However, in the condition $\beta_{\mathrm{Eth}}=8, \beta_{\mathrm{SES}}=8$ socioeconomic segregation would be much higher than in reality as the gray box at the bottom of Figure 5 shows. To avoid this over-segregation by SES that deviates from empirical observations, we consider the condition of tie-houses-to-SES, which preserves much of Bradford's sociodemographic structure. Note, nevertheless, that the role played by housing constraints on obtaining a realistic ethnic segregation scenario is minimal as compared to the role played by agents' 
SES preferences. The simulation stabilizes without ethnic over-segregation only when the weight for socioeconomic similarity outweighs ethnic similarity, with results similar to the ethnic empirical segregation in Bradford in 2011 ( $\beta_{\text {Eth }}=8, \beta_{\mathrm{SES}}=12$; see panel "Final constellation" in Figure 5). The mitigating effect that SES preferences have on ethnic segregation happens because some Asians accept less ethnically homogeneous neighborhoods to satisfy their SES preferences.

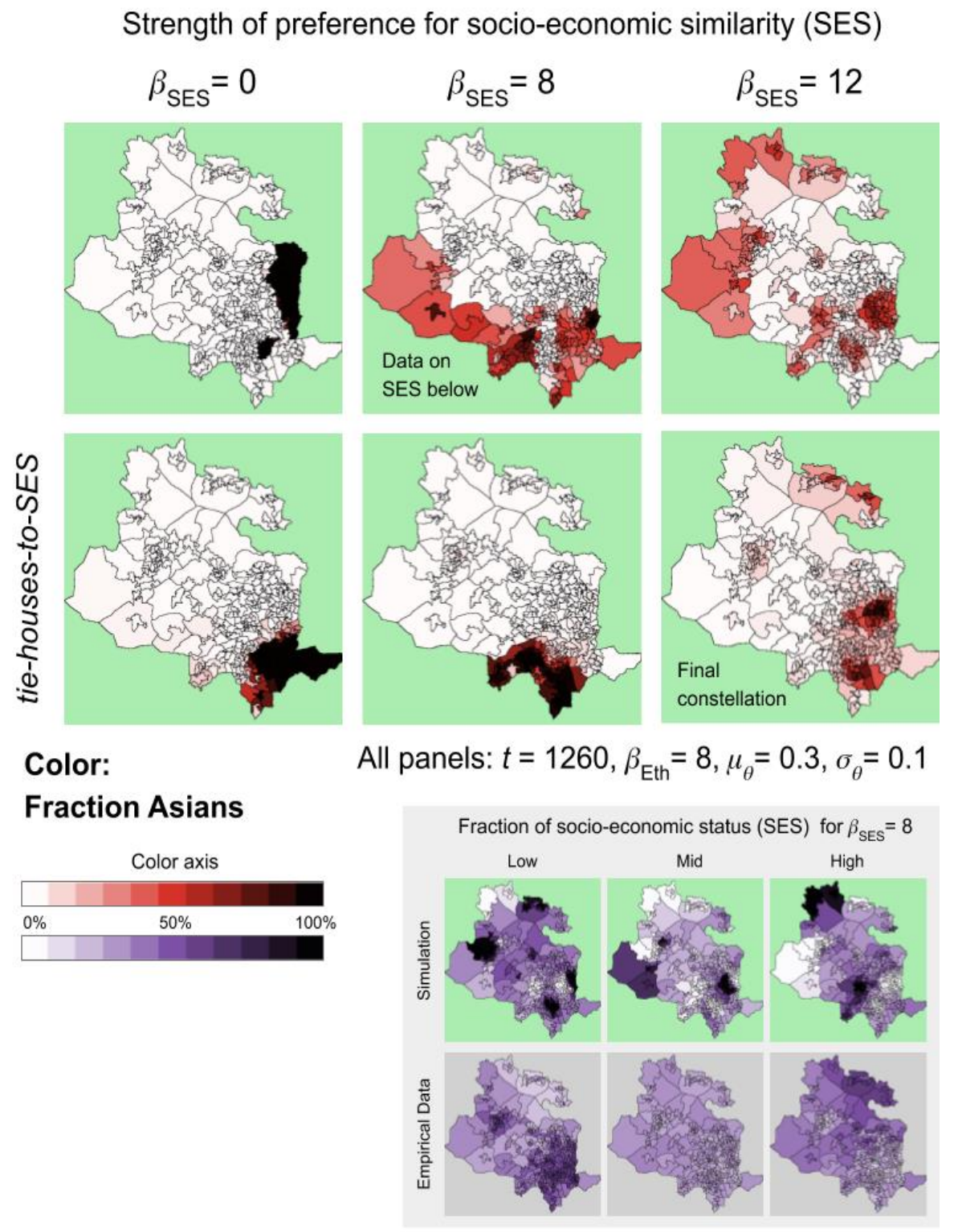

Figure 5: Exploration of the preferences for socioeconomic similarity and tying houses to socioeconomic status focusing on the fraction of Asians including the baseline parameter constellation. Further details about SES segregation for another simulation at the bottom.

\section{Summary and discussion}

Neighborhood ethnic segregation remains an issue in many societies and continues to feed debates on ethnic inequalities and on the routes towards social cohesion. Despite extensive literature on the changes and effects of segregation, a main challenge is to address the underlying processes that explain segregation as an aggregate emergent phenomenon derived from individuals' behaviors and their constraints (Bruch and Mare 2009b). Inspired by the field of analytical sociology and using agent-based modelling - a method that allows formalizing the link between individual decisions and emergent phenomena-our paper has helped filling in this gap. Specifically, we extended 
Schelling's agent-based model, and studied how ethnic and socioeconomic homophylic preferences and housing constraints interact to create varied emergent segregation patterns. We modeled the relocation decision of agents following a discrete choice random utility approach, simulating different weights for preferences for ethnic and socioeconomic similarity in neighborhood composition over random relocations. In addition, we included socioeconomic housing constraints to the actual relocation move. We used Bradford—a high ethnically segregated LA in the UK-as a case study and initialized our model with empirical geo-referenced data about ethnicity and SES from the 2011 Census.

Results show, as in the original Schelling model, that strong ethnic segregation would emerge as effect of relocation moves of individuals, also in case of mild preferences for ethnic similarity and starting from an artificially equalized spatial distribution. However, our additional consideration of socioeconomic factors in the model has proven to counterbalance this extreme result. We show that segregation patterns close to empirical observations, without ethnic over-segregation, are reached when preferences for socioeconomic similarity are slightly above the preferences for ethnic similarity. In particular, this dynamic seems to take place because Asians give up on ethnic homophily preferences to satisfy socioeconomic homophilic preferences, which is in line with some aspects of spatial assimilation theory and more generally with the well-known role that SES plays in ethnic segregation (Massey and Denton 1985, Malmberg and Clark 2020). While socioeconomic housing constraints do not seem to play a major role in ethnic segregation in our model, they do prevent over-segregation by SES, therefore improving the reproduction of Bradford's spatial structure overall.

Our work has important implications that can help enrich both policy (see e.g. HM Government 2021, 2018) and academic debates on segregation dynamics. This paper demonstrates, first, that spatial fractioning of ethnic communities might not necessarily reflect a prejudice towards other ethnic groups or the intention to self-segregate, as the 'parallel lives' thesis would state. Rather, high ethnic segregation can be the unintended consequence of simple relocation moves of individuals who want to satisfy their preferences to live close to just a few similar ones. In fact, ethnic preferences alone do not lead to a realistic picture of ethnic segregation in Bradford, but to over-segregation. Second, our results show that the process that leads to full segregation due to ethnic preferences can be altered in favor of less ethnic segregation when people care more about socioeconomic similarity. This means that, although tackling inter-group prejudice and promoting ethnic and migrant integration remain important for increasing ethnic mixing in neighborhoods and improving intercultural contact (see also Pettrachin et al. under review, Kelling and Monroe under review in this issue), investigating the role of socioeconomic factors in relocation decisions can also be helpful. This includes further explorations not only of the role of housing affordability (i.e., how individuals' SES match locations' SES), but also and most importantly on the reasons to live close to members of the same socio-economic class. Finally, by linking agent-based model and Schelling dynamics to geo-spatial Census data, we show the potential of computational approaches to study social and spatial processes (Drouhot et al. under review, Pettrachin et al. under review). Our freely available and reproducible model may also be useful to simulate policy interventions (e.g. a labor policy that impacts the distribution of SES across ethnic groups) and test their spatial consequences.

We acknowledge some limits of our work that can contribute to develop future lines of research. Even though we modeled a heterogeneous distribution of thresholds of agents, we did not differentiate their weights for ethnicity or socio-economic preferences (apart for ethnic preferences of Others). Although not a realistic assumption, this was done to not overly increase the complexity of the model so to better understand its dynamics. In the future, we could vary threshold or weights of individuals according to their ethnicity or socio-economic status, or as a combination of both to cover more detailed or realistic scenarios. Second, our model does not consider other factors affecting residential moves and/or spatial segregation more generally, such as ethnic discrimination, household composition, friendships and social networks, fertility, or migration patterns from/to 
Bradford. Further research would certainly benefit from including such dimensions in the models to observe how the mechanisms we identify would change or not. Finally, our results stem from the exploratory calibration of the model with Bradford data. In the future we could compare with other cities differing by ethnic or SES distribution in the population. This could shed further light on the role of population composition in causing our results and increase the generalizability of results to the UK context and beyond.

\section{Acknowledgements}

The collaboration was initiated at the BIGSSS Summer School in Computational Social Science on Migration 2019 in Sardinia, Italy http://css.bigsss-bremen.de/migration2019 funded by the Volkswagen Foundation. Rocco Paolillo received funding as doctoral student at the Bremen International Graduate School of Social Sciences while on the programme EU COFUND BIGSSSdeparts, Marie Skłodowska-Curie grant agreement no. 713639.

\section{References}

Aldén, Lina, Mats Hammarstedt, and Emma Neuman. 2015. "Ethnic segregation, tipping behavior, and native residential mobility." International Migration Review 49 (1):36-69. doi: doi:10.1111/imre.12066.

Belot, Michèle, and John Ermisch. 2009. "Friendship ties and geographical mobility: evidence from Great Britain." Journal of the Royal Statistical Society: Series A (Statistics in Society) 172 (2):427-442. doi: 10.1111/j.1467-985X.2008.00566.x.

Benard, Stephen, and Robb Willer. 2007. "A wealth and status-based model of residential segregation." The Journal of Mathematical Sociology 31 (2):149-174. doi: 10.1080/00222500601188486.

Boschman, Sanne, and Maarten Van Ham. 2015. "Neighbourhood selection of non-Western ethnic minorities: Testing the own-group effects hypothesis using a conditional logit model." Environment and Planning A 47 (5):1155-1174-1155-1174.

Bruch, Elizabeth E. 2014. "How population structure shapes neighborhood segregation." American Journal of Sociology 119 (5):1221-1278. doi: 10.1086/675411.

Bruch, Elizabeth E., and Robert D. Mare. 2006. "Neighborhood choice and neighborhood change." American Journal of sociology 112 (3):667-709-667-709.

Bruch, Elizabeth E., and Robert D. Mare. 2009a. "Preferences and pathways to segregation: Reply to van de Rijt, Siegel, and Macy." American Journal of Sociology 114 (4):1181-1198.

Bruch, Elizabeth E., and Robert D. Mare. 2009b. "Segregation dynamics." In The Oxford handbook of analytical sociology, edited by P. Hedström, P. S. Bearman and P. Bearman. Oxford: Oxford University Press.

Brynin, Malcolm, Simonetta Longhi, and Álvaro Martínez Pérez. 2008. The social significance of homogamy. edited by ISER. Essex: Institute for Social and Economic Research, University of Essex.

Carling, Alan. 2008. "The curious case of the mis-claimed myth claims: ethnic segregation, polarisation and the future of Bradford." Urban Studies 45 (3):553-589. doi: $10.1177 / 0042098007087335$.

Catney, Gemma. 2018. "The complex geographies of ethnic residential segregation: Using spatial and local measures to explore scale-dependency and spatial relationships." Transactions of the Institute of British Geographers 43 (1):137-152. doi: doi:10.1111/tran.12209.

Charles, Camille Zubrinsky. 2003. "The dynamics of racial residential segregation." Annual Review of Sociology 29 (1):167-207. doi: 10.1146/annurev.soc.29.010202.100002. 
Chen, Kan, Elena G. Irwin, Ciriyam Jayaprakash, and Keith Warren. 2005. "The emergence of racial segregation in an agent-based model of residential location: The role of competing preferences." Computational \& Mathematical Organization Theory 11 (4):333-338-333-338.

Clark, K., and S. Drinkwater. 2002. "Enclaves, neighbourhood effects and employment outcomes: ethnic minorities in England and Wales." Journal of Population Economics 15 (1):5-29. doi: 10.1007/pl00003839.

Clark, William A. V., and Mark Fossett. 2008. "Understanding the social context of the Schelling segregation model." Proceedings of the National Academy of Sciences 105 (11):4109-4114. doi: 10.1073/pnas.0708155105.

Clark, William A.V. , Maarten van Ham, and Rory Coulter. 2011. "Socio-spatial mobility in British society." IZA Discussion Paper 5861.

Coulter, Rory, and William A. V. Clark. 2018. "Ethnic disparities in neighbourhood selection: Understanding the role of income." International Journal of Urban and Regional Research (in press).

Coulter, Rory, Maarten van Ham, and Allan M. Findlay. 2016. "Re-thinking residential mobility: linking lives through time and space." Progress in Human Geography 40 (3):352-374. doi: $10.1177 / 0309132515575417$.

Crowder, Kyle, Scott J. South, and Erick Chavez. 2006. "Wealth, race, and inter-neighborhood migration." American Sociological Review 71 (1):72-94. doi: 10.1177/000312240607100104.

Drouhot, Lucas, Emanuel Deutschmann, Carolina V. Zuccotti, and Emilio Zagheni. under review. "Computational approaches to migration and integration research: promises and challenges." Journal of Ethnic and Migration Studies.

Edmonds, Bruce, Christophe Le Page, Mike Bithell, Edmund Chattoe-Brown, Volker Grimm, Ruth Meyer, Cristina Montañola-Sales, Paul Ormerod, Hilton Root, and Flaminio Squazzoni. 2019. "Different modelling purposes." Journal of Artificial Societies and Social Simulation 22 (3):6-6.

Epstein, J. M. 2006. Generative social science: Studies in agent-based computational modeling. Vol. 13. Princeton: Princeton University Press.

Erikson, Robert, and John Goldthorpe. 1992. The constant flux: a study of class mobility in industrial societies. Oxford: Clarendon Press.

Finney, Nissa, and Ludi Simpson. 2009. "Population dynamics: the roles of natural change and migration in producing the ethnic mosaic." Journal of Ethnic and Migration Studies 35 (9):1479-1496. doi: 10.1080/13691830903125935.

Fossett, Mark. 2006. "Ethnic preferences, social distance dynamics, and residential segregation: Theoretical explorations using simulation analysis." Journal of Mathematical Sociology 30 (34):185-273-185-273.

Fossett, Mark. 2011. "Generative models of segregation: investigating model-generated patterns of residential segregation by ethnicity and socioeconomic status." The Journal of Mathematical Sociology 35 (1-3):114-145. doi: 10.1080/0022250X.2010.532367.

Frankhauser, Pierre, and Dominique Ansel. 2016. Deciding where to live: An interdisciplinary approach to residential choice in its social context. Wiesbaden: Springer.

Galster, George, and Lena Magnusson Turner. 2019. "Status aversion, attraction and discrepancy as drivers of neighborhood selection." City \& Community 18 (3):937-964. doi: https://doi.org/10.1111/ cico.12435.

Goldthorpe, John. 2000. On sociology. Numbers, narratives, and the integration of research and theory. Oxford: Oxford University Press.

Harris, Richard. 2017. "Measuring the scales of segregation: looking at the residential separation of White British and other schoolchildren in England using a multilevel index of dissimilarity." Transactions of the Institute of British Geographers 42 (3):432-444. doi: doi:10.1111/tran.12181. 
Heath, Anthony, and Neli Demireva. 2013. "Has multiculturalism failed in Britain?" Ethnic and Racial Studies 37 (1):161-180. doi: 10.1080/01419870.2013.808754.

Hedström, Peter, and Peter Bearman. 2009. "What is analytical sociology all about? An introductory essay." In The Oxford Handbook of Analytical Sociology, edited by Peter Hedström and Peter Bearman, 3-26. Oxford: Oxford University Press.

Hegselmann, R. 2017. "Thomas C. Schelling and James M. Sakoda: The intellectual, technical, and social history of a model." Journal of Artificial Societies and Social Simulation, 20 (3).

Hess, Stephane, Andrew Daly, and Richard Batley. 2018. "Revisiting consistency with random utility maximisation: theory and implications for practical work." Theory and Decision 84 (2):181-204-181-204.

HM Government. 2018. Integrated communities strategy green paper: building stronger, more united communities. United Kingdom.

HM Government. 2021. Commission on Race and Ethnic Disparities: The Report. United Kingdom.

Huang, Q., D. C. Parker, T. Filatova, and S. Sun. 2014. "A review of urban residential choice models using agent-based modeling." Environment and Planning B: Planning and Design 41 (4):661-689.

Jivraj, Stephen, and Omar Khan. 2013. Ethnicity and deprivation in England: how likely are ethnic minorities to live in deprived neighbourhoods? In Dynamics of Diversity: evidence from the 2011 Census, edited by ESRC-CoDE: University of Manchester.

Kalmijn, Matthijs. 1998. "Intermarriage and homogamy: causes, patterns, trends." Annual Review of Sociology 24 (1):395-421. doi: 10.1146/annurev.soc.24.1.395.

Kelling, Claire, and Burt Monroe. under review. "Analyzing community reaction to refugees through text analysis of social media data." Journal of Ethnic and Migration Studies.

Knies, Gundi, Alita Nandi, and Lucinda Platt. 2016. "Life satisfaction, ethnicity and neighbourhoods: Is there an effect of neighbourhood ethnic composition on life satisfaction?" Social Science Research 60:110-124. doi: http://doi.org/10.1016/j.ssresearch.2016.01.010.

Krysan, Maria, and Kyle Crowder. 2017. Cycle of segregation: Social processes and residential stratification. New York: Russel Sage Foundation.

Lan, Tian, Jens Kandt, and Paul Longley. 2020. "Geographic scales of residential segregation in English cities." Urban Geograpby 41 (1):103-123. doi: 10.1080/02723638.2019.1645554.

Lazarsfeld, Paul, and Robert K. Merton. 1954. "Friendship as a social process: a substantive and methodological analysis." In Freedom and control in modern society, edited by M. Berger, T. Abel and C. H. Page, 18-66. New York: Van Nostrand.

León-Medina, Francisco J. 2017. "Analytical sociology and agent-based modeling: is generative sufficiency sufficient?" Sociological Theory 35 (3):157-178. doi: 10.1177/0735275117725766.

Lin, Nan. 2001. Social capital: a theory of social structure and action. Cambridge: Cambridge University Press.

Macy, M. W., and R. Willer. 2002. "From factors to actors: Computational sociology and agentbased modeling. ." Annual Review of Sociology 28 (1):143-166.

Malmberg, Bo, and William A. V. Clark. 2020. "Migration and neighborhood change in Sweden: the interaction of ethnic choice and income constraints." Geographical Analysis n/a (n/a). doi: $10.1111 /$ gean.12250.

Manley, David. 2021. "Segregation in London: a city of choices or structures?" In Urban socioeconomic segregation and income inequality: a global perspective, edited by Maarten van Ham, Tiit Tammaru, Rüa Ubarevičene and Heleen Janssen. Cham: Springer.

Manski, Charles F. 1977. "The structure of random utility models." Theory and decision 8 (3):229_ 254-229-254.

Manzo, Gianluca, ed. 2014. Analytical sociology: actions and networks. Chichester: John Wiley \& Sons. 
Massey, Douglas S., and Nancy A. Denton. 1985. "Spatial assimilation as a socioeconomic outcome." American Sociological Review 50 (1):94-106.

McPherson, Miller, Lynn Smith-Lovin, and James M Cook. 2001. "Birds of a feather: homophily in social networks." Annual Review of Sociology 27 (1):415-444. doi: 10.1146/annurev.soc.27.1.415.

Peach, Ceri. 2005. "Social integration and social mobility: spatial segregation and intermarriage of the Caribbean population in Britain." In Ethnicity, social mobility and public policy, edited by Glenn C. Loury, Tariq Modood and Steven M. Teles, 178-203. Cambridge: Cambridge University Press.

Pettrachin, Andrea, Lorenzo Gabrielli, Jisu Kim, Sarah Ludwig, and Steffen Pötzschke. under review. "Did exposure to asylum seeking migration affect the electoral outcome of the "Alternative für Deutschland" in Berlin? Evidence from the 2019 European elections." Journal of Ethnic and Migration Studies.

Phillips, Deborah. 2006. "Parallel lives? Challenging discourses of British Muslim selfsegregation." Environment and Planning D: Society and Space 24 (1):25-40. doi: 10.1068/d60j.

Rattansi, Ali. 2011. Multiculturalism: a very short introduction. Oxford: Oxford University Press.

Roscigno, Vincent J., Diana L. Karafin, and Griff Tester. 2009. "The complexities and processes of racial housing discrimination." Social Problems 56 (1):49-69. doi: 10.1525/sp.2009.56.1.49.

Schelling, Thomas C. 1969. "Models of segregation." The American Economic Review 59 (2):488493.

Schelling, Thomas C. 1971. "Dynamic models of segregation." The Journal of Mathematical Sociology 1 (2):143-186. doi: 10.1080/0022250X.1971.9989794.

Simpson, Ludi. 2007. "Ghettos of the mind: the empirical behaviour of indices of segregation and diversity." Journal of the Royal Statistical Society: Series A (Statistics in Society) 170 (2):405-424. doi: 10.1111/j.1467-985X.2007.00465.x.

Stephens, Nicole M., Hazel Rose Markus, and L. Taylor Phillips. 2014. "Social class culture cycles: how three gateway contexts shape selves and fuel inequality." Annual Review of Psychology 65 (1):611-634. doi: 10.1146/annurev-psych-010213-115143.

Train, Kenneth E. 2009. Discrete choice methods with simulation: New York: Cambridge university press.

Van de Rijt, Arnout, David Siegel, and Michael Macy. 2009. "Neighborhood chance and neighborhood change: A comment on Bruch and Mare." American Journal of Sociology 114 (4):1166-1180. doi: 10.1086/588795.

Wilensky, Uri. 1999. NetLogo. http:/ / ccl.northwestern.edu/netlogo: Center for Connected Learning and Computer-Based Modeling, Northwestern University, Evanston, IL.

Xie, Yu, and Xiang Zhou. 2012. "Modeling individual-level heterogeneity in racial residential segregation." Proceedings of the National Academy of Sciences 109 (29):11646-11651-1164611651.

Zuccotti, Carolina V. 2019. "Ethnicity and neighbourhood attainment in England and Wales: A study of second generations' spatial integration." Population, Space and Place:e2252. doi: $10.1002 /$ psp.2252.

Zuccotti, Carolina V. 2021. "La segregación étnica en Inglaterra a través del tiempo (2001-2011): un estudio comparativo de ocho áreas habitacionales." 2021. doi: 10.14198/ingeo.16307.

Zuccotti, Carolina V., and Lucinda Platt. 2017. "Does neighbourhood ethnic concentration in early life affect subsequent labour market outcomes? A study across ethnic groups in England and Wales." Population, Space and Place 23 (6):e2041. doi: doi:10.1002/psp.2041. 


\section{Online Annex}

\subsection{How does segregation emerge in the Schelling model?}

Consider two groups of agents (red and blue) who reside on a checkerboard that represents a city, so that each individual agent occupies a spot and considers the set of the eight surrounding agents as its own 'neighborhood'. Some spots are empty on the checkerboard. At each timestep, one agent can choose whether to stay or to leave. Its residential moves depend on homophily preferences based on color, with a certain threshold for in-group members. Imagine a red agent starts. If the percentage of other red agents in the neighborhood falls below the threshold, the agent relocates to one of the empty spots on the checkerboard, so to leave its previous spot in the old neighborhood empty. By doing so, the red agent changes the composition of both its previous neighborhood and its new one. In particular, the percentage of same-color agents decreases for other red agents left in the previous neighborhood, while it increases for other red agents in the new neighborhood. In this way, the previous neighborhood becomes less attractive for the remained red agents, who could leave when it is their turn to decide. On the contrary, the new neighborhood becomes more attractive both to other red agents who already live there (who are then more prone to stay) and potentially to unsatisfied red agents living in other neighborhoods. The same works for blue agents. Through the change in neighborhoods' compositions, therefore, the relocation decision of each agent has unwillingly a cascade effect on the next agent to decide. This enables a self-reinforcing dynamic so that some neighborhoods become progressively less attractive for agents of one group and more attractive for those of the other group. In other words, the concentration of one group in the neighborhood reinforces its attractiveness for other in-group members when they decide to relocate. This, in turn, can lead to high segregation - even with relatively tolerant agents.

\subsection{Data and variables: further details}

Our analysis uses aggregated Census data (2011) obtained for Bradford at small geographical levels, the Lower Layer Super Output Areas (LSOAs). LSOAs are aggregations of Output Areas (which were designed to have similar population sizes and be as socially homogenous as possible). England counts 32,844 LSOAs in 2011, out of which 306 belong to Bradford. LSOAs in Bradford have an average of 1700 individuals, and a median 1800. The most populated LSOAs are also the smallest in terms of the area they occupy and are in Bradford's city center. As for the geographical information, we obtained the map of Bradford, with its LSOAs, from http://geoportal.statistics.gov.uk. Geographical data from the shapefile was then merged to the Census data.

We collected information of SES by ethnic group at the LSOA level. We identified four ethnic groups, using the Census question on ethnic self-identification: White British, Asian, Black, and Other ethnic groups (includes other White and mixed groups). Although most ethnic minority groups are represented in Bradford, Asians constitute the majority (around one quarter of the total population, mostly from Pakistani origin; while the White British population was $64 \%$ in 2011, and the Black population 3\%). Our analysis, therefore, pays particular attention to explaining the distribution of the Asian group. As regards the socioeconomic dimension, we used individuals' socioeconomic status or social class. An individual's social class is one of the best indicators of their socioeconomic resources and positioning in the social structure (Goldthorpe 2000); it also tends to be quite stable over time, compared for example with other socioeconomic indicators such as income or employment status. We measure social class with a standard measure commonly used in the UK: The National Statistics Socio-Economic Classification (NS-SEC) (Erikson and Goldthorpe 1992). We used grouped categories: High (classes 1 \& 2: large employers, higher and lower managerial, administrative, and professional occupations), Mid (classes $3 \& 4$ : intermediate occupations, small employers, and own-account 
workers), and Low (classes 5, $6 \&$ \%: routine and semi-routine occupations and lower supervisory and technical occupations). Our ABM analysis is therefore based on Census information making up 12 categories for each LSOA: three SES categories by four ethnic groups.

The NS-SEC classification is calculated for individuals aged $16+$, and excludes those who never worked, the long-term unemployed and full-time students. This means that our ABM analysis leaves out individuals who do not have a valid SES measure: for White British individuals, this constitutes around 10\%, but this is much higher for ethnic minorities (Asians 42\%, Blacks 34\% and Other 27\%). While this might appear as a limitation given that we are not considering the entire population, working with population $16+$ is a better proxy of potential movers, bearing in mind that residential mobility decisions are often made by adults at the household level (Coulter, van Ham, and Findlay 2016, Clark, van Ham, and Coulter 2011). An alternative would have been to obtain ethnicity and SES for the household head, or more detailed information on family composition by ethnicity and SES. However, this information is not available from the publicly available Census statistics. Furthermore, considering household composition would have made the simulations more complex and would have deviated from our key aim of exploring the link between ethnic and SES preferences. Note also that even though two partners in a couple might have different SES, and therefore potentially have different preferences on where to live, we expect the impact of this to be limited, first, because homogamy is a widespread phenomenon in many countries around the world (Kalmijn 1998), including the UK (Brynin, Longhi, and Pérez 2008), and second, because many ethnic minority women actually do not have a valid SES (since they have never worked) and they would therefore most likely be attached to the men's preferences. As for other members without a valid SES, they are mostly children, students and young adults who never worked, and who also most likely follow their parents in their residential choices. Finally, note also that the spatial correlation between the full population in LSOAs and those who have a valid SES is very high for the two groups that predominate in Bradford: White British and Asians (0.99); and somehow smaller but still high for Blacks (0.93) and Others (0.82). The restriction to valid SES also changes the shares of ethnic groups: White British $=76 \%$, Asian $=16 \%$, Black $=2 \%$ and Other $=6 \%$.

\subsection{Segregation indices and Moran Index}

For an ethnic group $X$ the Dissimilarity Index is

$$
D^{X}=\frac{\sum_{i} \frac{N_{i}}{N_{\text {Town }}} \cdot\left|P_{i}^{X}-P_{\text {Town }}^{X}\right|}{2 P_{\text {Town }}^{X}\left(1-P_{\text {Town }}^{X}\right)}
$$

where where $P_{i}^{X}$ indicates the fraction of individuals for ethnic group $X$ in LSOA $I, P_{\text {Town }}^{X}$ the fraction in the whole town, $N_{i}$ the number of individuals in LSOA $i$ and $N_{\text {Town }}$ the number of individuals in the whole town. The denominator is to normalize the Dissimilarity index to lie between zero and one.

The Simpson Index is a measure of ethnic concentration. Calculated for one LSOA $i$ as $S_{i}=$ $\sum_{X}\left(P_{i}^{X}\right)^{2}$. The lower $S_{i}$, the more ethnically diverse is the LSOA. The maximal value is achieved when the district is populated exclusively by one ethnic group. Note that we only sum the squares of the fractions of White British, Asians, and Blacks, leaving outside "other ethnic groups". The Simpson Index is mathematically closely related to entropy, a measure of disorder which is also sometimes used in segregation studies to quantify the unequal distribution of ethnic groups between neighborhoods or between the global and the local level. 
The Average Local Simpson Index is:

$$
S=\sum_{i}\left(\frac{N_{i}}{N_{\text {Town }}} \sum_{X}\left(P_{i}^{X}\right)^{2}\right)
$$

The Moran Index (Moran-I) is expressed as:

$$
\text { Moran }-\mathrm{I}=\frac{L}{W} \frac{\sum_{i} \sum_{j} w_{i j}\left(v_{i}-\bar{v}\right)\left(v_{j}-\bar{v}\right)}{\sum_{i}\left(v_{i}-\bar{v}\right)^{2}}
$$

Where $v_{i}$ are the values in the LSOAs and $\bar{v}$ their average. The weights $w_{i j}$ are one when LSOA $i$ and $j$ share a border and zero otherwise. Finally, $L$ is the number of LSOA and $W$ the number of positive $w_{i j}$.

\subsection{ABM: Model Reproduction}

We build our model in NetLogo (Wilensky 1999) and made it freely available along with supplemental material. ${ }^{19}$ NetLogo is a free software for building and experimenting on agentbased models and was developed under continuous development by Uri Wilensky's team at Northwestern University. It comes as an integrated development environment (IDE), including a code editor to build the agent-based model with programming language (Scala, Java) and an interface where the observer can interact with the model itself. The interface of our model is shown in Figure 5 (main text). Here we show how to use the model to reproduce results showed in the text, giving more detailed information on how it works and how it interacts with GIS information.

1) Clicking "Load town to Sim" in the Interface Section "1. Load Town from GIS Data" initializes the simulation by loading the LSOA shapes of a town using NetLogo's GIS extension. The GIS data includes population count data for each LSOA as the 4-by-3 matrix for the four ethnic and three socioeconomic groups. Summary statistics of the whole town are shown in the output window on the left. From the population data, a set of agents is created in each district. Agents are initialized with ethnicity and socioeconomic status according to population data in census tract 2011. Further on, each agent draws the threshold $\theta$ for ethnic and socio-economic similarity from a Beta distribution with mean $\mu_{\theta}$ and standard $\sigma_{\theta}$. Finally, the maximal population is set for each LSOA upon initialization. ${ }^{20}$ The population data can be visually explored on the central map using the switches (e.g. "show-links"), choosers (e.g. "measure", "ethnicity", "ses"), and sliders (e.g. "threshold-mean") in the section "2. Explore Local Data". Several basic, segregation specific, and other measures are available. Many are for specific ethnic or socioeconomic groups or both.

2) Clicking "Shuffle Population" in section "3. Setup Simulation" creates a counterfactual situation in which each district shows the same composition of ethnicities as the whole town. All our simulation experiments shuffle the population as part of the initialization

\footnotetext{
19 The model can be found at https://github.com/janlorenz/Schelling_on_GIS

20 The maximal population is set based on the free-space parameter which quantifies the fraction of free places compared to the initial population. The maximal population is set once for the whole population for each district and once for each socioeconomic status group. The latter allows to tie houses to agents with a specific socioeconomic status which is an option that can be switched on and off at runtime.
} 
procedure to find conditions for the emergence of segregation in towns initially not segregated. Shuffling keeps the geography of LSOAs, the total decomposition of the population into ethnicity, and socioeconomic groups. The shuffling procedure takes the parameter tie-houses-to-SES into account. Consequently, the dissimilarity for all ethnic groups and the average local Simpson Index are maximally low.

3) Clicking "Go" in the interface section "4. Run Simulation" starts a simulation run. Further on, the section provides the global parameters from the utility functions $\beta_{\text {Eth }}$ and $\beta_{\mathrm{SES}}$ which can be changed at runtime. Once "Go" is clicked, the simulation runs one tick after the other. In each tick, agents are picked at random and perform the two-step decision to relocate as described in the text. The total number of agent decisions per tick matches the total number of agents. Thus, a tick represents a unit time step in which on average every agent thinks about relocation once.

4) The central monitor called "World" in NetLogo, shows how the simulation evolves at each tick. To the right, the Section "5. Outcomes Simulation vs. Empirical" compares the results from the simulation with empirical observed data. Measures refer to the options selected in Section 2 "Explore Local Data" and then "Update Maps and Plots". The first panel shows the distribution of the LSOAs' fraction of selected groups, where the x-axis are all districts sorted by size. Besides to the right is the same information as a histogram. time trends below are shown for the average local Simpson index. The panel below shows the dissimilarity indices for all four ethnic groups including the other ethnic groups. The last bottom panel shows the fraction of agents who search and who finally move in one-time step.

5) The particular simulation outcome of Figure 5 showed in the text can be inspected in more detail by loading the saved simulations provided with the model in NetLogo via "Import World" in Section 1 "Load Town from GIS Data", selecting the relevant measures, and "Update Maps and Plots". The supplemental material in the available repository provides the NetLogo model file, geographic and demographic data for Bradford to be loaded in NetLogo, and all simulations presented here.

6) Section "Further Parameters" concerns other available options that were not included in the baseline parameter constellations and parameter decomposition. Parameter "Further Outcomes" show the Isolation index, i.e. the probability a random person with ethnicity $\mathrm{x}$ interacts in district with person of ethnicity $y$ and related options. This outcome is not reported in the paper. 
Time evolution of the fraction of Asians in the final constellation $\beta_{\mathrm{Eth}}=8, \beta_{\mathrm{SES}}=12, \mu_{\theta}=$ $0.3, \sigma_{\theta}=0.1$, tie-houses-to-SES, $\boldsymbol{t}=\mathbf{0}, \mathbf{2 0}, \mathbf{6 0}, \mathbf{1 4 0}, \mathbf{3 0 0}, \mathbf{6 2 0}, \mathbf{1 2 6 0}, 2540$

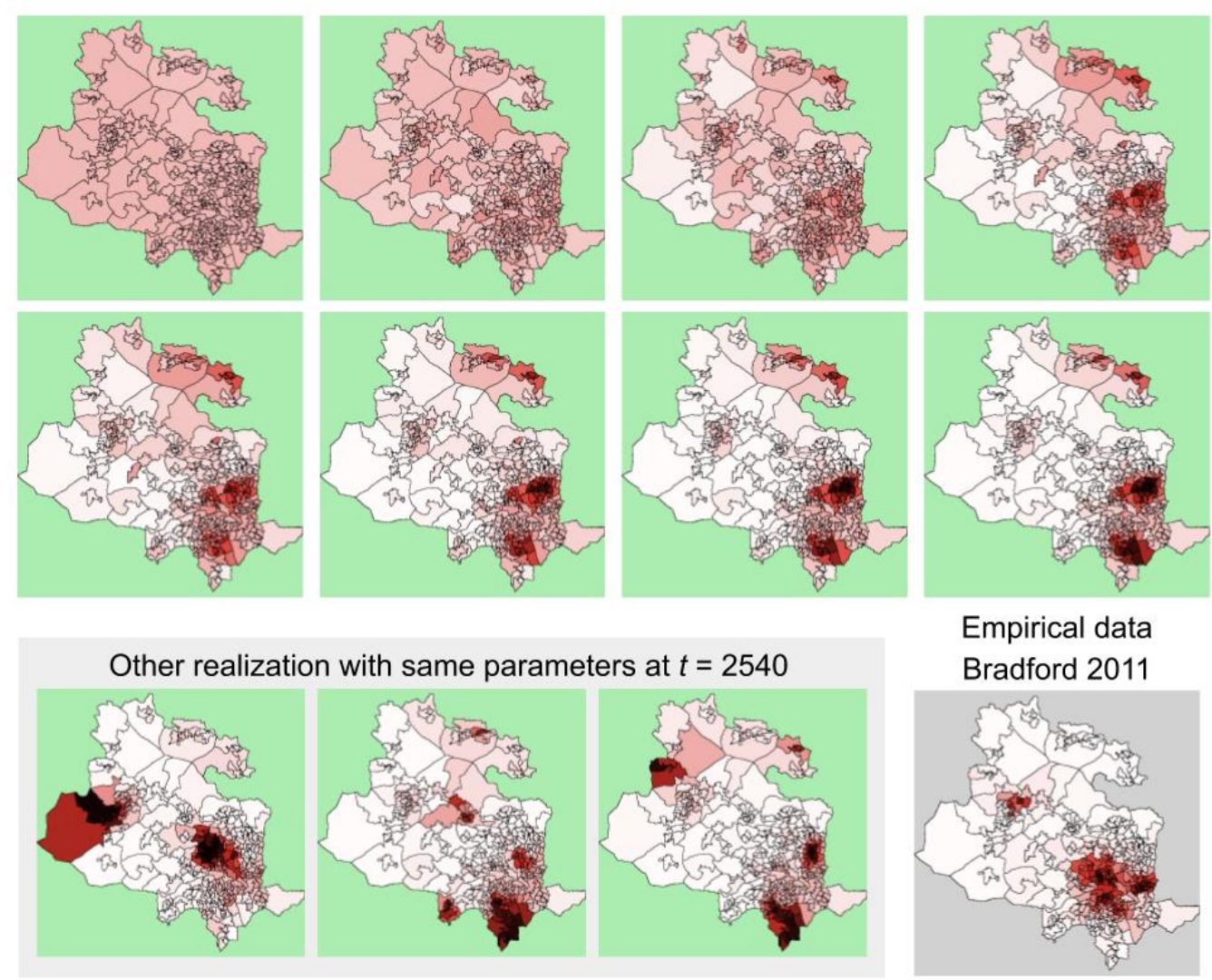

Figure A1: Time evolution of the fraction of Asians in the main simulation of the baseline parameter constellation. For comparison: Three other realizations and the emprical situation in Bradford 2011.

Figure A1 shows the evolution of Asians' segregation in the baseline parameter constellation of the agent-based model described in Figure 5 in the text. At time step $t=0$, Asians are evenly distributed within the city of Bradford. For time $t=20$ and 60, the relocations of Asians show not high segregation, as due to random relocations described in mechanisms (1-2). At time $t=$ 140, a few LSOA's where Asians already reside become attractor to other Asians who decided to relocate, as explained by mechanism (3). The bottom line for time $t=300,620,1260$ and 2540 show the passage from mechanism (3) to mechanism (4) scenarios: as the critical mass of $70 \%$ Asians is reached, other ethnicities (British Whites) will leave, causing the emergence of full-Asian districts. The bottom left figure shows how similar results would emerge, even if different LSOAs where to become the full-Asian districts, meaning no coincidence between spatial geography and emerged segregation patterns, as effect of initial even distributed condition. 


\subsection{References for Annex}

Brynin, Malcolm, Simonetta Longhi, and Álvaro Martínez Pérez. 2008. The social significance of homogamy. edited by ISER. Essex: Institute for Social and Economic Research, University of Essex.

Clark, William A.V. , Maarten van Ham, and Rory Coulter. 2011. "Socio-spatial mobility in British society." IZA Discussion Paper 5861.

Coulter, Rory, Maarten van Ham, and Allan M. Findlay. 2016. "Re-thinking residential mobility: linking lives through time and space." Progress in Human Geography 40 (3):352-374. doi: $10.1177 / 0309132515575417$.

Goldthorpe, John. 2000. On sociology. Numbers, narratives, and the integration of research and theory. Oxford: Oxford University Press.

Kalmijn, Matthijs. 1998. "Intermarriage and homogamy: causes, patterns, trends." Annual Review of Sociology 24 (1):395-421. doi: 10.1146/annurev.soc.24.1.395.

Wilensky, Uri. 1999. NetLogo. http:// ccl.northwestern.edu/netlogo: Center for Connected Learning and Computer-Based Modeling, Northwestern University, Evanston, IL. 